Provided for non-commercial research and education use. Not for reproduction, distribution or commercial use.

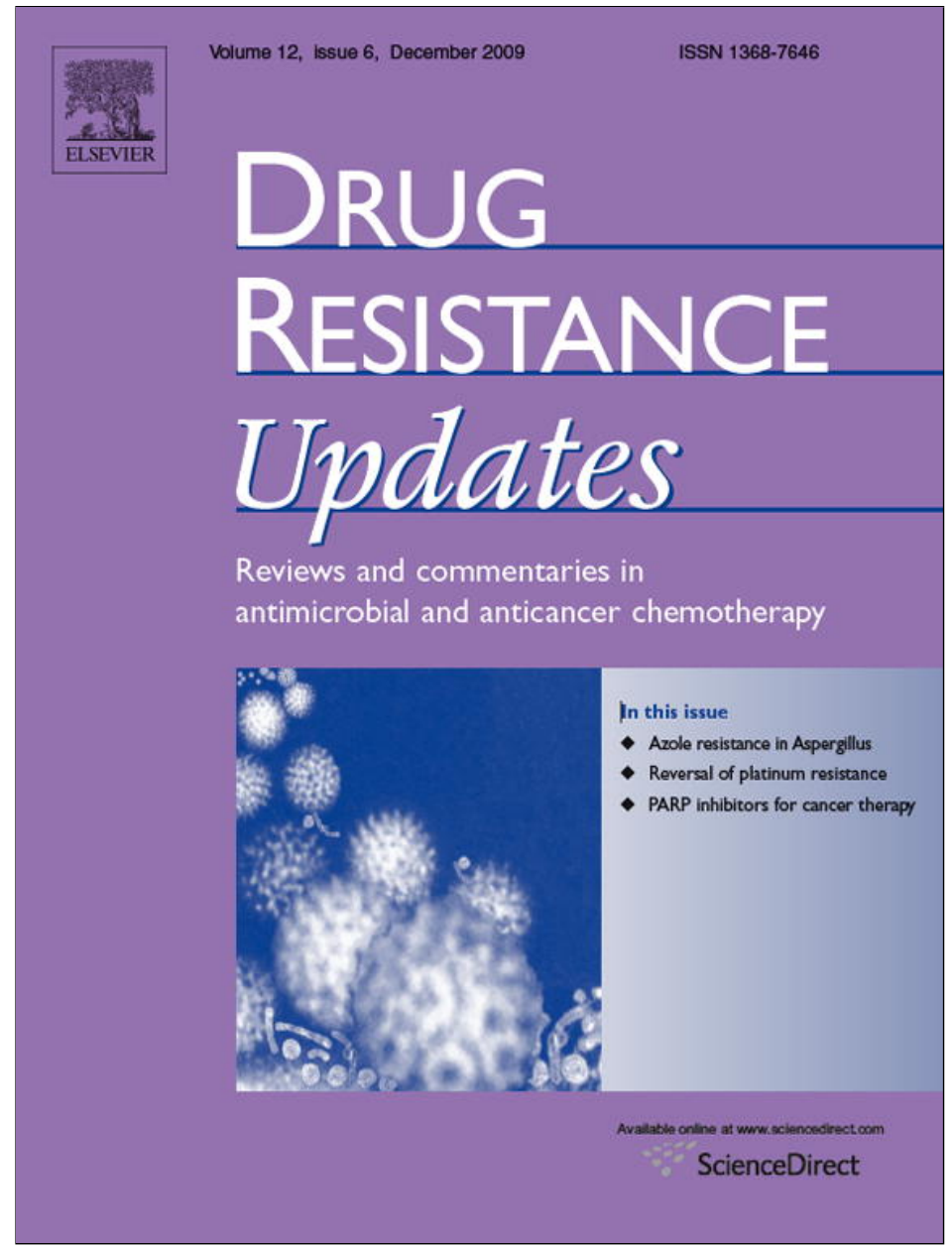

This article appeared in a journal published by Elsevier. The attached copy is furnished to the author for internal non-commercial research and education use, including for instruction at the authors institution and sharing with colleagues.

Other uses, including reproduction and distribution, or selling or licensing copies, or posting to personal, institutional or third party websites are prohibited.

In most cases authors are permitted to post their version of the article (e.g. in Word or Tex form) to their personal website or institutional repository. Authors requiring further information regarding Elsevier's archiving and manuscript policies are encouraged to visit:

http://www.elsevier.com/copyright 


\title{
Azole-resistance in Aspergillus: Proposed nomenclature and breakpoints
}

\author{
Paul E. Verweij ${ }^{\mathrm{a}}$, Susan J. Howard ${ }^{\mathrm{b}}$, Willem J.G. Melchers ${ }^{\mathrm{a}}$, David W. Denning ${ }^{\mathrm{b}, *}$ \\ a Department of Medical Microbiology, Radboud University, Nijmegen Medical Centre, The Netherlands \\ ${ }^{\mathrm{b}}$ The National Aspergillosis Centre, The University of Manchester and University Hospital of South Manchester, Manchester, United Kingdom
}

\section{A R T I C L E I N F O}

\section{Article history:}

Received 18 April 2009

Accepted 8 June 2009

\begin{abstract}
A B S T R A C T
Reports of itraconazole resistance in Aspergillus fumigatus have been more frequent since the millennium. Identifying azole resistance is critically method dependent; nevertheless reproducible methods, reflective of in vivo outcome, are now in routine use. Some isolates also have elevated MICs to posaconazole and voriconazole. Multiple mechanisms of resistance are now known to be responsible, with differing degrees of azole cross-resistance, including mutations in the Cyp51A gene at G54, L98 + TR, G138, M220, G448. Establishing breakpoints for Aspergillus is probably impossible with clinical data alone for multiple reasons yet there is an urgent need to do so. We propose the following breakpoints for A. fumigatus complex using the proposed EUCAST susceptibility testing methodology: for itraconazole and voriconazole, $<2 \mathrm{mg} / \mathrm{L}$ (susceptible), $2 \mathrm{mg} / \mathrm{L}$ (intermediate) and $>2 \mathrm{mg} / \mathrm{L}$ (resistant); for posaconazole, $<0.25,0.5$ and $>0.5 \mathrm{mg} / \mathrm{L}$ respectively. We recognize that additional work will be needed to confirm these proposed breakpoints, including in vivo and clinical correlative responses. We also propose nomenclature for genotypic resistance, in the event an isolate is not cultured, typified by ITZgR, VCZgI, POSgR (G54W) indicating that the isolate has a G54W substitution with a corresponding phenotype of resistance to itraconazole and posaconazole and intermediate susceptibility to voriconazole.
\end{abstract}

(c) 2009 Elsevier Ltd. All rights reserved.

\section{Introduction}

Aspergillus species cause a wide range of diseases including allergic syndromes, chronic pulmonary and nasal sinus aspergillosis and acute and subacute invasive disease. Azoles increasingly play a role in the management of Aspergillus diseases. Itraconazole is commonly used for the treatment of chronic and allergic conditions (Denning et al., 2003), while voriconazole is first choice therapy for invasive aspergillosis (Herbrecht et al., 2002; Walsh et al., 2008). The triazole posaconazole has been shown to be effective in preventing invasive aspergillosis in patients with certain hematologic malignancies (Cornely et al., 2007; Ullmann et al., 2007). Besides azoles, only amphotericin B and the echinocandins (caspofungin, micafungin, anidulafungin) have any useful clinical activity, with better evidence supporting amphotericin B for primary therapy of invasive aspergillosis (Walsh et al., 2008).

Although Aspergillus species are generally susceptible to the above mentioned compounds, intrinsic and acquired resistance has been documented. Amphotericin B has limited activity against Aspergillus terreus (Johnson et al., 1999; Walsh et al., 2003; Steinbach et al., 2004), and A. nidulans (Kontoyiannis et al., 2002),

\footnotetext{
* Corresponding author at: 2nd Floor Education \& Research Centre, University Hospital of South Manchester, Southmoor Road, Manchester, M23 9LT, United Kingdom. Tel.: +44 161291 5811; fax: +441612915806.

E-mail address: ddenning@manchester.ac.uk (D.W. Denning).
}

while A. calidoustus (previously known as A. ustus) appears to be intrinsically resistant to triazole compounds (Varga et al., 2008). Furthermore, several species in the Aspergillus fumigatus complex (A. lentulus, A. pseudofisheri and A fumigatiaffinis) appear to be intrinsically resistant to azoles, and in the case of $A$. lentulus and A. fumigatiaffinis resistant to amphotericin B as well (Balajee et al., 2005).

Several studies indicate that acquired resistance of Aspergillus species to triazoles is uncommon (Pfaller et al., 2008; Guinea et al., 2008). However, in reference mycology laboratories in both Manchester, United Kingdom, and Nijmegen, The Netherlands, azole-resistance in Aspergillus species has emerged since 1998 (Fig. 1) (Verweij et al., 2007; Snelders et al., 2008; Howard et al., 2009). In these centres acquired resistance was primarily observed in A. fumigatus, although in Manchester resistance was also observed in other species such as A. niger complex (Howard et al., 2006a, 2008). In addition, azole-resistance was found in clinical A. fumigatus isolates from all eight University Hospitals in the Netherlands (Snelders et al., 2008; Van der Linden et al., 2008), and resistance was reported in Spain (Mellado et al., 2007), Belgium (Lagrou et al., 2008), Denmark (Arendrup et al., 2008), Sweden (Chryssanthou, 1997), France (Dannaoui et al., 2001), and Norway (Snelders et al., 2008). The isolates originally described with itraconazole resistance were from the USA and isolated in the late 1980s (Denning et al., 1997a). Therefore, it appears that azole resistance might be more common than currently acknowledged and clinical microbiology laboratories should determine the in vitro 


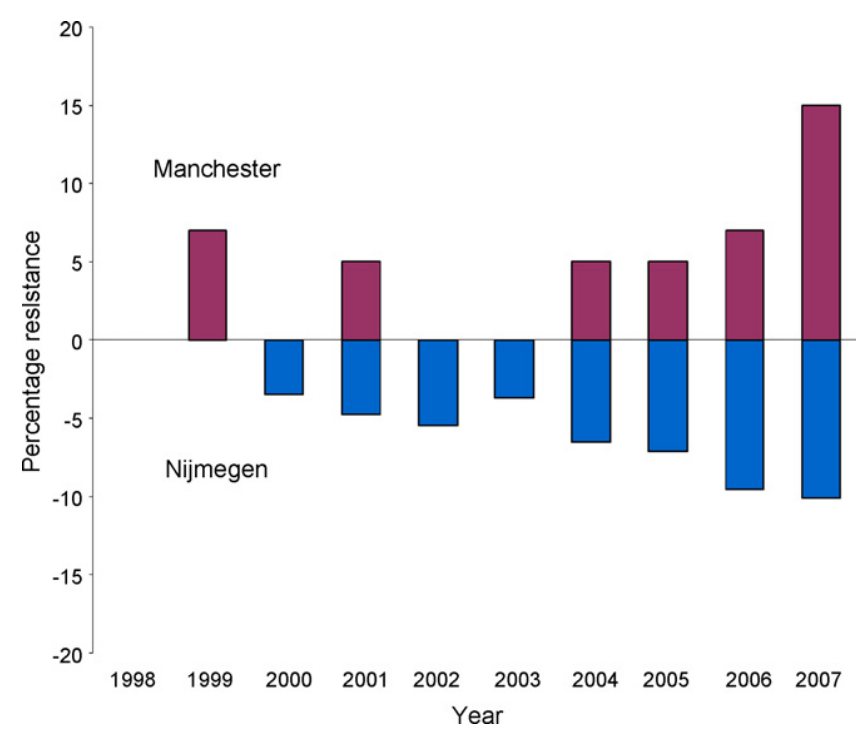

Fig. 1. Percentage of patients with azole-resistant A. fumigatus strains in Manchester, United Kingdom, and Nijmegen, the Netherlands (1998-2007).

susceptibility of clinically relevant Aspergillus isolates, at least against the triazoles, which is currently not common practice.

Numerous resistance mechanisms have been found in azoleresistant A. fumigatus isolates, most of which consist of point mutations in the cyp51A gene, which is the target for antifungal azoles, as well as alteration in expression of CYP51A. The corresponding phenotype depends on the particular base substitution and often the activity of more than one triazole is affected, and in the absence of interpretative breakpoints this has resulted in various nomenclatures in the literature. Azole-resistant isolates have been reported as "multidrug resistant" (Warris et al., 2002), "multiazole resistant" (Howard et al., 2006b), "azole cross-resistant" (Pfaller et al., 2008), and "multiple-triazole resistant" (Verweij et al., 2007; Snelders et al., 2008). Therefore, there is an increasing need to develop breakpoints in order to obtain consistency in the nomenclature of resistance in A. fumigatus isolates, for clinical purposes. Here we propose interpretative breakpoints based on a review of the literature and on our own experience.

\section{Establishing interpretative breakpoints}

The normal means of establishing interpretative breakpoints for culturable microorganisms requires a number of preconditions to be met at the start. A key requirement is a reproducible means of establishing an endpoint, which is usually an inhibitory (static) endpoint rather than a cidal endpoint. A second key requirement is the availability of isolates which are resistant to the agent(s) in question. In this context, documentation by clinical failure (including breakthrough on treatment) is the typical means of obtaining such isolates. Subsequent confirmation of lack of response can be modeled in animal or in in vitro models to increase confidence and establish pharmacodynamic parameters. Generally, isolates with high levels of resistance are better for the initial process of establishing susceptibility testing methodology. Some isolates obtained from clinical failure have intermediate minimum inhibitory concentrations (MICs) or are susceptible, but other factors lead to clinical failure (low drug concentration, drug-drug interactions, unresolved profound immunodeficiency, infected foci that did not receive surgical attention etc.). Then usually follows a period of refinement of susceptibility testing to better separate susceptible and resistant isolates with the method and understand which parameters have a major influence on MIC endpoint. Typically, these include inoculum, growth rate and endpoint reading, but as Rambali showed (Rambali et al., 2001), even subtle methodological factors can individually or collectively impact on endpoint over a wide range. Once an optimal method is established, it is necessary to assess reproducibility in different laboratories with different readers. Quality control strains are required for this process, the key characteristic of which is to give highly reproducible results over many $10 \mathrm{~s}$ or 100 s of tests, ideally in the midpoint of the proposed drug concentration range. For A. fumigatus, A. flavus and $A$. terreus this work has been done and quality control strains proposed (Cuenca-Estrella et al., 2007). To test for variation with the same isolate is also established by these experiments, which is important as interpretative breakpoints must allow for this normal variation in results.

Using the optimal and reproducible susceptibility testing method, wild-type distributions of MICs are then established, with 100 s or 1000 s of clinical isolates. This has been spectacularly well achieved by EUCAST for large numbers of clinical isolates from numerous clinical centres (Cuenca-Estrella et al., 2003). If there are very few isolates with elevated MICs found in the clinic, the need for an interpretative breakpoint is diminished, but more pragmatically it is very difficult to set any breakpoint.

Two approaches have been broadly used for establishing MIC breakpoints to date. The first is to compare rates of clinical failure of a given species with an antimicrobial agent, for example Candida albicans and fluconazole (Rex et al., 1997). Treatment failure of oral candidiasis with different doses of fluconazole provided the first consistent examples of azole resistance in fungi, and the rates of failure at different doses (which correlate well with different drug exposures) provided a range of choices for interpretative MIC breakpoints. Ultimately, the final determination of breakpoint is a choice of an unacceptably high failure rate, since there is rarely a dichotomous outcome of elevated MIC and 100\% clinical failure. The second approach utilizes wild-type distributions of individual species and antimicrobial agent (Rodríguez-Tudela et al., 2007). Sometimes a clear-cut, bimodal distribution of MICs is seen, in which case selection of a breakpoint is relatively straightforward, depending on the separation of the peaks, the proportion of isolates in the crossover zone and the variation in MIC determination. Other times a bimodal distribution is not seen, and indeed other data suggest that the single distribution range encompasses both susceptible and resistant isolates. Unless the reproducibility of MIC determination is highly precise and reproducible - which is rarely the case with fungal susceptibility testing - establishing a breakpoint is not advisable by these means as it would lack adequate clinical utility.

There are specific difficulties in attempting to establish a clinically derived breakpoint for the Aspergilli. These include the highly variable bioavailability and patient azole exposure related to genetic variability, formulation, age, food intake and co-administration of other drugs, the infrequent occurrence of monotherapy of sufficient duration to establish success or failure in invasive disease, the low frequency of culture positive cases, a lack of alternative (surrogate) markers of success or failure, highly variable background immunodeficiency states which change over time (i.e. recovery of neutropenia) and substantial differences in severity (and body site) of illness and critical differences in the speed of diagnosis and initiation of treatment (Table 1 ). A major practical detail is that cultures are infrequently positive and so MICs are not obtainable. Use of allergic syndromes for this purpose, presupposes that only antifungal activity drives clinical success in treatment of these entities, which may or may not be a valid assumption.

On the other hand, derivation of breakpoints by wild-type epidemiological distribution is possible for those antifungal agents that display a bimodal distribution of MICs (i.e. itraconazole and A. fumigatus). Assuming that sufficient isolates in the putative 
Table 1

Factors which mitigate against establishing a clinical MIC breakpoint for the Aspergilli, based on clinical response to treatment.

\begin{tabular}{|c|c|}
\hline $\begin{array}{l}\text { Factor impacting on } \\
\text { clinical interpretation } \\
\text { of therapeutic response }\end{array}$ & Comment \\
\hline $\begin{array}{l}\text { Variable bioavailability } \\
\text { of oral azoles }\end{array}$ & $\begin{array}{l}\text { Substantial differences in oral absorption, } \\
\text { common with itraconazole and to a lesser } \\
\text { extent with posaconazole, relate to food } \\
\text { intake, } \mathrm{H} 2 \text { blockers or PPIs, and } \\
\text { formulation of itraconazole. }\end{array}$ \\
\hline $\begin{array}{l}\text { Variable metabolism } \\
\text { and exposure }\end{array}$ & $\begin{array}{l}\text { All azoles have substantial inter-patient } \\
\text { variation, especially voriconazole, which } \\
\text { varies }>100 \text {-fold in adults, and more so in } \\
\text { children. Some centres monitor levels and } \\
\text { adjust doses, others do not. }\end{array}$ \\
\hline Drug-drug interactions & $\begin{array}{l}\text { All azoles are susceptible to accelerated } \\
\text { metabolism with cytochrome p } 450 \\
\text { inducers. Some are susceptible to reduced } \\
\text { metabolism, i.e. voriconazole and } \\
\text { omeprazole, resulting in highly variable } \\
\text { exposures. }\end{array}$ \\
\hline $\begin{array}{l}\text { Common use of } \\
\text { combination and } \\
\text { sequential therapy }\end{array}$ & $\begin{array}{l}\text { As failure rates with all the current agents } \\
\text { remain too high and untreated invasive } \\
\text { aspergillosis has a } \sim 100 \% \text { mortality, } \\
\text { combination therapy is commonly } \\
\text { employed and switches from IV to oral } \\
\text { agents common, before an assessment of } \\
\text { response is possible. }\end{array}$ \\
\hline $\begin{array}{l}\text { Clinical outcome is } \\
\text { affected by underlying } \\
\text { disease }\end{array}$ & $\begin{array}{l}\text { Some patients with reversible } \\
\text { immunosuppression may respond well } \\
\text { because of improvement in the immune } \\
\text { status (i.e. recovery of neutropenia) and } \\
\text { others with untreatable relapse leukaemia } \\
\text { will fare badly. Neither are good tests of a } \\
\text { relationship of MIC to treatment outcome. }\end{array}$ \\
\hline $\begin{array}{l}\text { Speed of diagnosis and } \\
\text { initiation of therapy }\end{array}$ & $\begin{array}{l}\text { The speed with which a diagnosis of } \\
\text { invasive aspergillosis can be made is a } \\
\text { major factor in clinical response. }\end{array}$ \\
\hline $\begin{array}{l}\text { Responses vary by } \\
\text { organ affected }\end{array}$ & $\begin{array}{l}\text { Certain localisations of invasive } \\
\text { aspergillosis are more difficult to treat, i.e. } \\
\text { brain, heart valve etc. }\end{array}$ \\
\hline $\begin{array}{l}\text { Different Aspergillus } \\
\text { diseases }\end{array}$ & $\begin{array}{l}\text { Invasive aspergillosis may be angioinvasive } \\
\text { or not and these pathologies differ } \\
\text { substantially from chronic pulmonary and } \\
\text { allergic bronchopulmonary aspergillosis. } \\
\text { Breakpoints derived for one manifestation } \\
\text { of aspergillosis may not reflect breakpoints } \\
\text { for another. }\end{array}$ \\
\hline $\begin{array}{l}\text { Low frequency of } \\
\text { culture positive cases }\end{array}$ & $\begin{array}{l}\text { Most cases of invasive and chronic } \\
\text { pulmonary aspergillosis are culture } \\
\text { negative, making an MIC determination } \\
\text { impossible. }\end{array}$ \\
\hline $\begin{array}{l}\text { Infections caused more } \\
\text { than one isolate }\end{array}$ & $\begin{array}{l}\text { Occasional infections are caused by more } \\
\text { than one isolate of Aspergillus, of the same } \\
\text { or different species, which may or may not } \\
\text { be cultured. The isolates may have } \\
\text { different susceptibility to antifungal } \\
\text { agents. }\end{array}$ \\
\hline
\end{tabular}

resistance range have demonstrable mechanisms of resistance, providing internal consistency between in vivo failure, elevated MIC and common mechanisms of resistance, MICs associated with resistance can be defined. The challenge is to define the precise boundary between susceptible and resistant. Use of the term intermediate (or indeterminate) may suffice if few isolates have these MICs.

A few data suggest that a genotypic determination of resistance could provide a better means of establishing resistance, for some antimicrobial agent/microorganism combinations. Sometimes there is an excellent correlation between an MIC and the absence or presence of a one or more molecular markers of resistance (for example mecA, mecl and mecR1 in Staphylococcus aureus) (Krishnan et al., 2002). In Candida species, drug efflux is responsible for the majority of azole resistance and is related to over-expression of one or more transporter genes, although target site mutations may also be responsible. A multiplicity of mechanisms and overexpression of one or more genes is not likely to be amenable to straightforward genotypic resistance markers. In contrast, particular mutations conferring flucytosine resistance correlated better than MICs with in vivo outcome by either the CLSI or EUCAST methodology, in a set of 6 isolates of $C$. albicans (Hope et al., 2006). For such methods to be adopted in clinical practice, rapid determinations of resistance genotype need to be available, and the impact on susceptibility of any particular mutation must be profound and unequivocal.

\section{Methods for MIC testing in Aspergillus species}

Various formats have been developed to test the susceptibility of Aspergilli; including macro/micro broth dilution, disc diffusion and Etest (Lass-Florl and Perkhofer, 2008). In recent years there have been advances with the development of Clinical Laboratory Standards Institute (CLSI; formerly NCCLS) M38-A (NCCLS, 2002), and European Committee for Antibiotic Susceptibility Testing (EUCAST) methods for filamentous fungi (SAST, 2007). Both methods include a microtitre format, 48 -h incubation at $35-37^{\circ} \mathrm{C}$ and a no growth visual endpoint. The main differences between the two standards are; inoculum preparation by spectrophotometer versus haemocytometer, inocula of $0.4-5 \times 10^{4}$ versus $2-5 \times 10^{5} \mathrm{cfu} / \mathrm{mL}, 0.2 \%$ glucose versus $2 \%$ glucose for CLSI and EUCAST respectively. A check on the inoculum is important for high levels of reproducibility as the MIC is partially inoculum dependent for certain isolates (Mosquera and Denning, 2002; Mosquera et al., 2001). Several modifications to the standards have been carefully studied and may provide solutions to the limitations of the methods currently available.

Improved MIC determinations has led to more reproducible and accurate detection of resistance, which has benefited the study of resistance mechanisms. Further development with newer antifungal drugs and interpretative breakpoints will continue this process.

\section{Mechanisms of resistance in Aspergillus species}

Several mechanisms of resistance have been described in Aspergilli. Azole resistance has most commonly been associated with alterations in cyp51A, the gene encoding the target enzyme of the azoles. The most frequently characterized hot spots are at codons 54, 98 and 220, although several other single nucleotide polymorphisms (SNPs) have been reported (Verweij et al., 2007; Snelders et al., 2008; Mellado et al., 2004, 2007; Howard et al., 2006b; Chen et al., 2005). Codon 98 mutations were always accompanied by a tandem repeat in the promoter region (TR/L98H), which increases cyp51A expression; importantly both alterations are essential to confer resistance (Snelders et al., 2008; Mellado et al., 2007). The contribution of other mechanisms, such as reduced intracellular concentration by efflux pumps (Slaven et al., 2002) and reduced uptake of the drug (Manavathu et al., 1999), has been proposed. Mounting evidence suggests the role of multiple mechanisms contributing to the overall phenotype.

The distribution of resistance mechanisms differ between the Dutch and British azole-resistant isolates, with the TR/L98H substitution being highly dominant in the Dutch isolates and several Cyp51A mutations being present in the British isolates (Snelders et al., 2008). The reasons for these differences are not clear and might be related to differences in the patient populations from which such isolates were cultured. For the Dutch isolates, it is certainly possible that azole resistance might develop in the environment rather than during treatment of individual patients - due to exposure of $A$. fumigatus to azole fungicides that are commonly used for plant and material protection (Snelders et al., 2008). Indeed $A$. 
Table 2

Link between genotype and phenotype in azole-resistant $A$. fumigatus isolates.

\begin{tabular}{|c|c|c|c|c|}
\hline \multirow[t]{2}{*}{ Genotype } & \multicolumn{3}{|c|}{ MIC (mg/L) Phenotype } & \multirow[t]{2}{*}{ Reference $^{\mathrm{a}}$} \\
\hline & ITR & VOR & POS & \\
\hline G54 & $>8$ & $0.125-1$ & 1 to $>8$ & $\begin{array}{l}\text { Chen et al. (2005), Mann et al. (2003), Diaz-Guerra et al. } \\
\text { (2003), Nascimento et al. (2003), Howard et al. (2006c), } \\
\text { Manavathu et al. (2003) }\end{array}$ \\
\hline $\mathrm{L} 98 \mathrm{H}+\mathrm{TR}$ & $>8$ & 0.5 to $>8$ & $0.5-4$ & $\begin{array}{l}\text { Mellado et al. (2007), Hodiamont et al. (2009), Van der Linden } \\
\text { et al. (2009) }\end{array}$ \\
\hline G138 & $>8$ & 2 to $>8$ & 1 to $>8$ & Howard et al. (2006b,c), Manavathu et al. (2003) \\
\hline M220 & $>8$ & $0.5-4$ & 0.125 to $>8$ & $\begin{array}{l}\text { Mellado et al. (2004), Chen et al. (2005), Diaz-Guerra et al. } \\
\text { (2003), Howard et al. (2006c) }\end{array}$ \\
\hline G448 & $>8$ & $>8$ & $0.5-2$ & Manavathu et al. (2003) \\
\hline
\end{tabular}

a Also from unpublished data, Manchester, UK.

fumigatus isolates resistant to medical azoles were recovered from environmental sources such as soil and compost (Snelders et al., 2009).

Cross-resistance between different azoles is recognized and it is an important clinical factor, with relatively few therapeutic choices for Aspergillus infections, in particular oral options. Table 2 summarises the current data linking phenotype to genotype for various cyp51A mutations. Not only the position of the alteration within the gene, but also the specific amino acid substitution contributes to the pattern of cross-resistance (Mann et al., 2003; Xiao et al., 2004). Examples of cross-resistant phenotypes, determined by Etest, are shown in Fig. 2.

\section{In vivo data on Aspergillus resistance}

Numerous data indicate that it is possible to distinguish itraconazole susceptible and resistant isolates of $A$. fumigatus in animal models of infection (Arendrup et al., 2008; Denning et al., 1997a,b; Oakley et al., 1997; Dannaoui et al., 2001). Confidence in the results require a model using isolates with widely differing clear-cut numerical endpoints for susceptible and resistant isolates, which has historically been mortality, but increasingly is colony forming units or genome equivalents. Biomarkers such as galactomannan or beta 1,3-D-glucan could be used, if well studied, but have not been yet. All endpoints other than mortality require referencing to mortality, which has clearly demonstrated the link between high itraconazole MICs in vitro and failure of treatment, with adequate drug exposure, in the case of A. fumigatus. Recently the efficacy of posaconazole was evaluated in a murine model against three $A$. fumigatus isolates with different cyp51A substitutions, conferring different in vitro susceptibilities to the drug (Mavridou et al., 2008). There was a clear association between the MIC and efficacy in the animal model, with increasing MIC corresponding with decreasing efficacy (Mavridou et al., 2008). Thus far, no in vivo resistance studies have been published with voriconazole.

There is a limited number of reported cases that help us to understand the clinical impact of azole resistance on clinical outcome. As indicated above, there are numerous other factors that
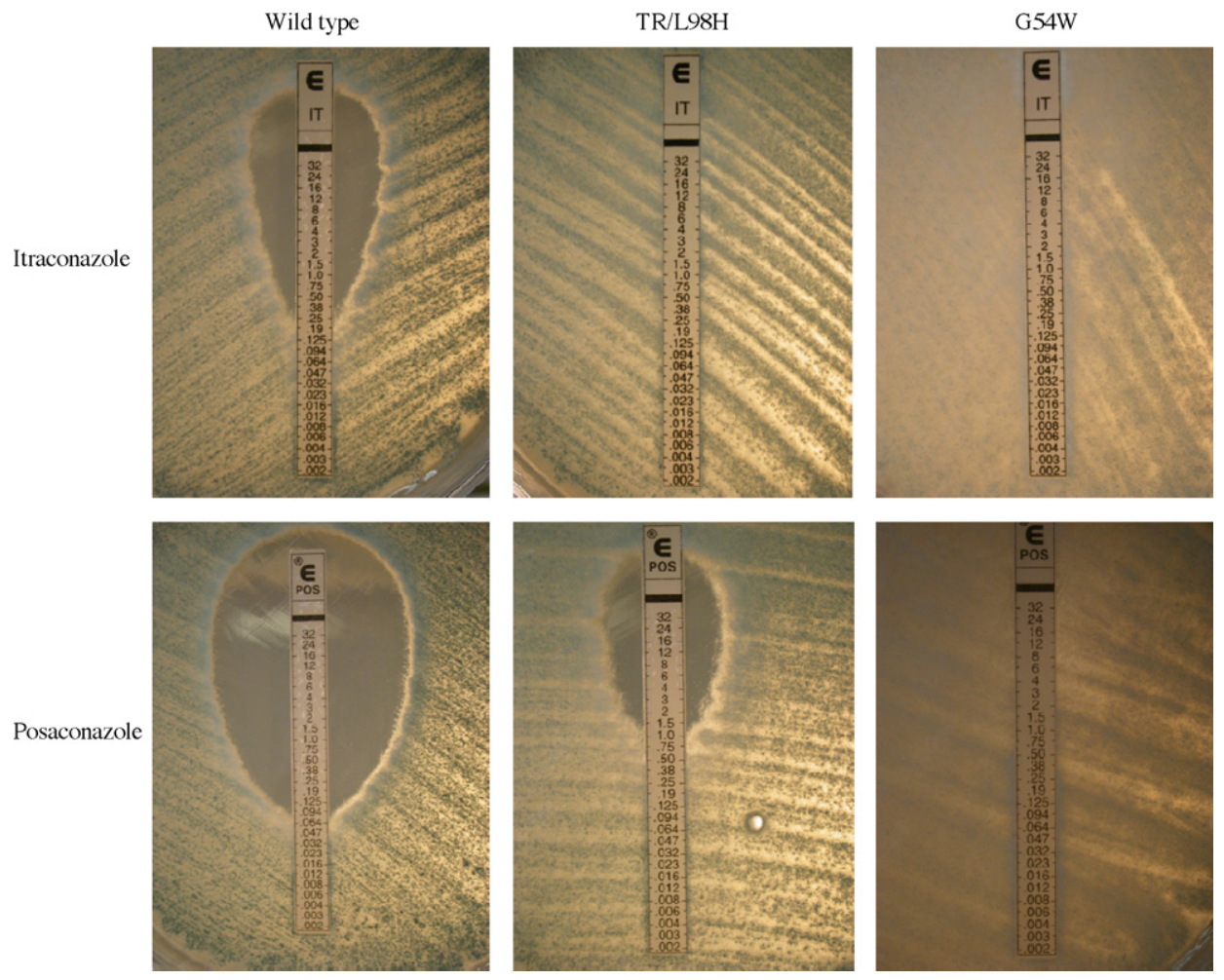

Fig. 2. MICs of itraconazole and posaconazole in three clinical A. fumigatus isolates determined by Etest. The MICs of itraconazole and posaconazole are 0.25 and 0.064 mg/L, respectively, for the wild-type isolate (left panel). Itraconazole shows no activity against the isolate with the TR/L98H substitution, while the MIC of posaconazole is $1 \mathrm{mg} / \mathrm{L}$ (middle panel). Both itraconazole and posaconazole show no in vitro activity against the isolate with a G54W substitution (right panel). 
determine the outcome of treatment including reduction of the underlying immunodeficiency and surgical intervention. However, the resistance mechanism and corresponding phenotype appear to impact on the therapeutic response. Azole-resistant invasive aspergillosis has been reported to present as breakthrough infection in patients on itraconazole prophylaxis and voriconazole therapy, indicating that these drugs were less effective, although other explanations such as low bioavailability cannot be disregarded (Verweij et al., 2007; Snelders et al., 2008). Primary invasive infections due to resistant isolates have been reported involving the lung (Verweij et al., 2007; Howard et al., 2009a), bone (Hodiamont et al., 2009) and brain (Van der Linden et al., 2009; Howard et al., 2009a) as well from respiratory isolates in allergic bronchopulmonary aspergillosis (Howard et al., 2009b). Lack of clinical efficacy of itraconazole has also been shown in patients with aspergilloma (Howard et al., 2006b, 2009a; Chen et al., 2005). At present, there is no evidence that the activity and efficacy of other classes of antifungal compounds, such as the polyenes and echinocandins, is attenuated in azole-resistant isolates (Verweij et al., 2007; Snelders et al., 2008). Based on these reports and our own experience, we recommend the use of a non-azole class drug or echinocandin/polyene combination in initial therapy of cases of azole-resistant invasive aspergillosis.

Either voriconazole or posaconazole may be useful for itraconazole-only resistant chronic or allergic aspergillosis, depending on the MIC and the ability to increase drug exposure in the patient. One patient with chronic granulomatous disease and disseminated invasive aspergillosis due to an A. fumigatus isolate harbouring the $\mathrm{L} 98 \mathrm{H} / \mathrm{TR}$ genotype responded to a high dose of voriconazole. The MIC of the isolate of voriconazole was $2 \mathrm{mg} / \mathrm{L}$ (Warris et al., 2002). In other patients, with azole-resistant isolates with a MIC of $0.5 \mathrm{mg} / \mathrm{L}$, posaconazole has been successfully used for follow-up therapy (Verweij et al., 2007; Hodiamont et al., 2009). This indicates that voriconazole or posaconazole might remain therapeutic options for those isolates with an increased MIC compared to wild-type isolates. Dose escalation is preferred against isolates with an increased MIC, although saturation of the absorption of posaconazole at doses greater than $800 \mathrm{mg}$ per day may preclude increased drug exposure based on volunteer studies. Ensuring adequate drug exposure by measuring plasma drug concentrations is probably important in these cases, as MICs are often raised, even if 'susceptible'. This is important given the lack of alternative antifungal agents that can be administered orally.

\section{Proposed breakpoints/nomenclature}

The emergence of azole resistance in Aspergilli has lead to confusing nomenclature in the literature which primarily relates to the fact that SNP-containing isolates might be fully resistant to one azole but show full or reduced susceptibility to other azoles. Therefore it is important to establish breakpoints that will help us to interpret the MIC. As the formal procedure for determination of interpretative breakpoints will take many years to complete, we propose to follow a pragmatic approach and propose breakpoints on the basis of MIC distribution, PK/PD of antifungal azoles, in vivo experimental correlation between SNPs and failure, and clinical experience. Table 3 outlines our proposed interpretative breakpoints for Aspergilli and Fig. 3 shows the relation between these breakpoints and the MIC distribution for 325 consecutive clinical A. fumigatus isolates from the Nijmegen fungal culture collection. The proposed breakpoints discriminate between the wild-type and non-wild-type distribution for itraconazole and voriconazole. As there is still limited evidence that infections with isolates with elevated MICs can be safely treated with a higher dose of these azoles,
Table 3

Proposed interpretative breakpoints (MIC, $\mathrm{mg} / \mathrm{L}$ ) for A. fumigatus and clinically licensed, active azoles.

\begin{tabular}{llll}
\hline Drug & Susceptible & Intermediate & Resistant \\
\hline Itraconazole & $<2$ & 2 & $>2$ \\
Voriconazole & $<2$ & 2 & $>2$ \\
Posaconazole & $<0.5$ & 0.5 & $>0.5$ \\
\hline
\end{tabular}

we choose not to use the susceptible-dose-dependent (SDD) category. For posaconazole an intermediate category was chosen for isolates with MICs of $0.5 \mathrm{mg} / \mathrm{L}$. Although a large proportion of the non-wild-type isolates are within the intermediate category, the limited ability to increase drug exposure with the oral solution and the results of preliminary animal experimental data indicate that the probability of failure for isolates with intermediate MICs is significant.

Based on these breakpoints, names can be defined by the different phenotypic profiles they encompass. We propose a
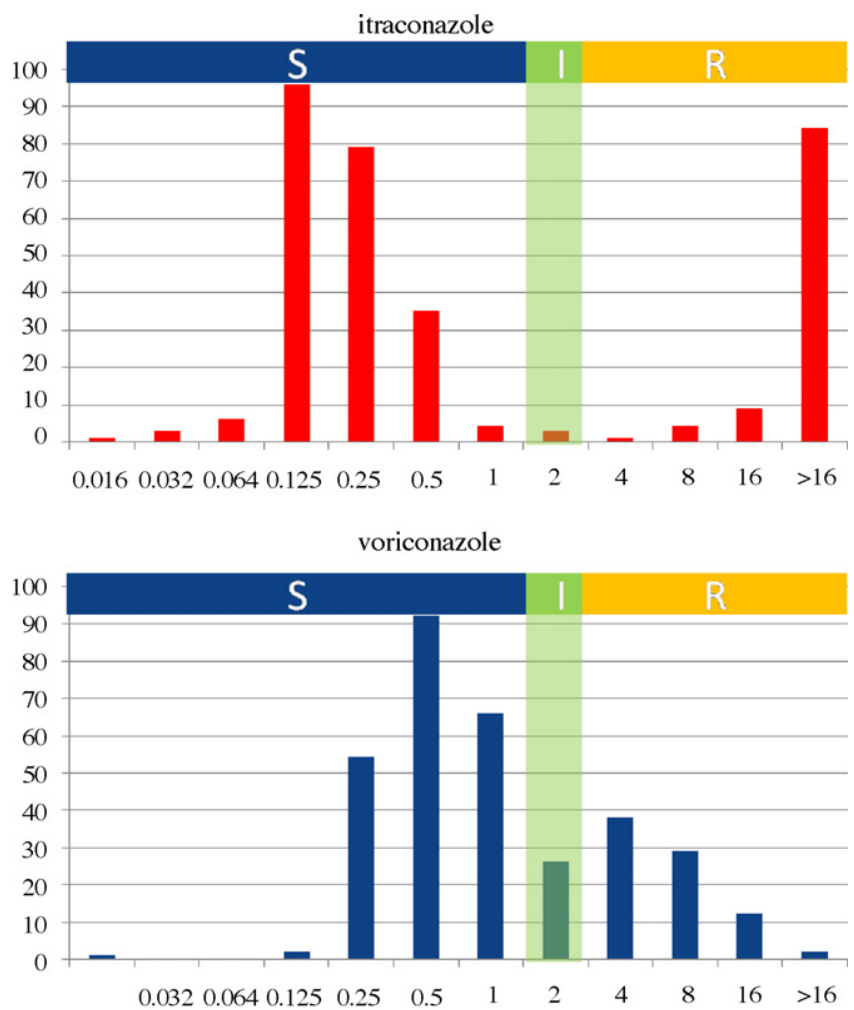

posaconazole

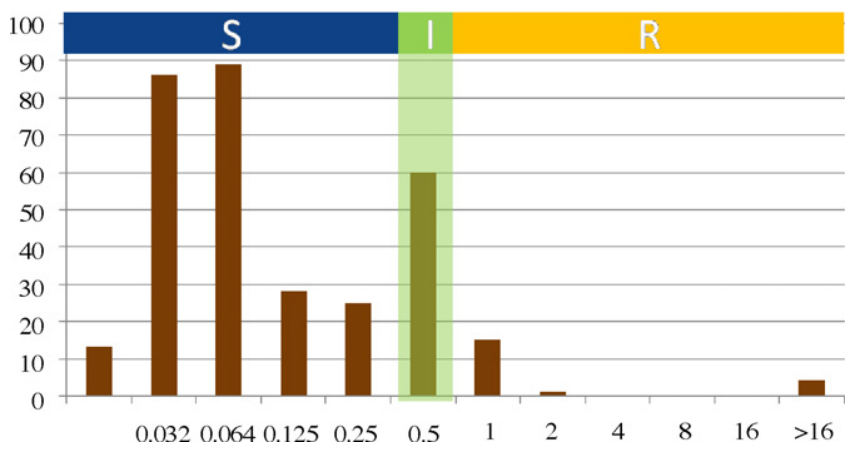

Fig. 3. Relationship between MIC distribution of 325 consecutive MIC determinations of clinical A. fumigatus isolates from the Nijmegen fungus culture collection and the proposed breakpoints. The MIC $(\mathrm{mg} / \mathrm{L})$ is given on the $X$-axis and the number of isolates on the $Y$-axis. Categories: $\mathrm{S}$, susceptible; I, intermediate; R, resistant. 
Table 4

Proposed nomenclature of resistance in Aspergilli to clinically licensed azoles.

\begin{tabular}{lll}
\hline Phenotype & Name & Description \\
\hline Multi-azole resistant & $\begin{array}{l}\text { The MICs of the isolate are in the } \\
\text { resistant range for all available } \\
\text { active azoles. } \\
\text { The MICs are in the resistant range } \\
\text { for more than one, but not all, } \\
\text { azoles. }\end{array}$ \\
Thenotype & $\begin{array}{l}\text { The Mics are in the resistant range } \\
\text { for a single azole. }\end{array}$ \\
& $\begin{array}{l}\text { voriconazole or } \\
\text { posaconazole resistant } \\
\text { ITZR, VCZgI, POSgR } \\
\text { (G54W) }\end{array}$ & $\begin{array}{l}\text { Isolate has a G54W substitution } \\
\text { with a corresponding phenotype of } \\
\text { resistance to itraconazole and } \\
\text { posaconazole and intermediate } \\
\text { susceptibility to voriconazole. }\end{array}$ \\
\hline
\end{tabular}

nomenclature that differentiates between resistance to a single azole, more than one azole or all clinically available azoles (Table 4). The genotype can be indicated by adding " $\mathrm{g}$ " with the phenotype abbreviated by R (resistant), I (intermediate) and S (susceptible), with the substitution added between parentheses (Table 4).

\section{Conclusion}

As with virtually all antimicrobial agents, azole resistance has emerged in the Aspergilli and has launched a new phase in our handling of aspergillosis. The proposed breakpoints and nomenclature will help us interpret the different azole-resistant forms and communicate within the scientific community. Continued surveillance for resistance is required, as is continued search for new resistance mechanisms. Genotypic methods of resistance identification may provide more confidence, given the limitations of culture and susceptibility testing. The clinical implications of azole resistance in terms of management and outcome requires our urgent attention and alternative antifungal drugs are required for oral use, given the present lack of alternative oral options in azole-resistant aspergillosis.

\section{References}

Arendrup, M.C., Perkhofer, S., Howard, S.J., Garcia-Effron, G., Vishukumar, A Perlin, D., Lass-Flörl, C., 2008. Establishing in vitro-in vivo correlations for Aspergillus fumigatus: the challenge of azoles vs. echinocandins. Antimicrob. Agents Chemother. 52, 3504-3511.

Balajee, S.A., Gribskov, J.L., Hanley, E., Nickle, D., Marr, K.A., 2005. Aspergillus lentulus sp. nov., a new sibling species of A. fumigatus. Eukaryot. Cell 4, 625-632.

Chen, J., Li, H., Li, R., Bu, D., Wan, Z., 2005. Mutations in the cyp51A gene and susceptibility to itraconazole in Aspergillus fumigatus serially isolated from a patient with lung aspergilloma. J. Antimicrob. Chemother. 55, 31-37.

Chryssanthou, E., 1997. In vitro susceptibility of respiratory isolates of Aspergillus species to itraconazole and amphotericin B acquired resistance to itraconazole. Scand. J. Infect. Dis. 29, 509-512.

Cornely, O.A., Maertens, J., Winston, D.J., Perfect, J., Ullmann, A.J., Walsh, T.J., Helfgott, D., Holowiecki, J., Stockelberg, D., Goh, Y.T., Petrini, M., Hardalo, C., Suresh, R., Angulo-Gonzalez, D., 2007. Posaconazole vs. fluconazole or itraconazole prophylaxis in patients with neutropenia. N. Engl. J. Med. 356, 348 359.

Cuenca-Estrella, M., Moore, C.B., Barchiesi, F., Bille, J., Chryssanthou, E., Denning, D.W., Donnelly, J.P., Dromer, F., Dupont, B., Rex, J.H., Richardson, M.D., Sancak, B., Verweij, P.E., Rodríguez-Tudela, J.L., AFST Subcommittee of the European Committee on Antimicrobial Susceptibility Testing, 2003. Multicenter evaluation of the reproducibility of the proposed antifungal susceptibility testing method for fermentative yeasts of the Antifungal Susceptibility Testing Subcommittee of the European Committee on Antimicrobial Susceptibility Testing (AFST-EUCAST). Clin. Microbiol. Infect. 9, 467-474.

Cuenca-Estrella, M., Arendrup, M.C., Chryssanthou, E., Dannaoui, E., Lass-Florl, C., Sandven, P., Velegraki, A., Rodriguez-Tudela, J.L., AFST Subcommittee of EUCAST 2007. Multicentre determination of quality control strains and quality contro ranges for antifungal susceptibility testing of yeasts and filamentous fungi using the methods of the Antifungal Susceptibility Testing Subcommittee of the European Committee on Antimicrobial Susceptibility Testing (AFST-EUCAST). Clin. Microbiol. Infect. 13, 1018-1022.
Dannaoui, E., Borel, E., Monier, M.F. Piens, M.A., Picot, S., Persat, F., 2001. Acquired itraconazole resistance in Aspergillus fumigatus. J. Antimicrob. Chemother. 47, 333-340.

Denning, D.W., Radford, S.A., Oakley, K.L., Hall, L., Johnson, E.M., Warnock, D.W., 1997a. Correlation between in-vitro susceptibility testing to itraconazole and in-vivo outcome of Aspergillus fumigatus infection. J. Antimicrob. Chemother. 40 401-414.

Denning, D.W., Venkateswarlu, K., Oakley, K.L., Anderson, M.J., Manning, N.J., Stevens, D.A., Warnock, D.W., Kelly, S.L., 1997b. Itraconazole resistance in Aspergillus fumigatus. Antimicrob. Agents Chemother. 41, 1364-1368.

Denning, D.W., Riniotis, K., Dobrashian, R., Sambatakou, H., 2003. Chronic cavitary and fibrosing pulmonary and pleural aspergillosis: case series, proposed nomenclature change, and review. Clin. Infect. Dis. 37 (Suppl. 3), S265-S280.

Diaz-Guerra, T.M., Mellado, E., Cuenca-Estrella, M., Rodriguez-Tudela, J.L., 2003. A point mutation in the 14alpha-sterol demethylase gene cyp51A contributes to itraconazole resistance in Aspergillus fumigatus. Antimicrob. Agents Chemother. $47,1120-1124$.

Guinea, J., Recio, S., Peláez, T., Torres-Narbona, M., Bouza, E., 2008. Clinical isolates of Aspergillus species remain fully susceptible to voriconazole in the postvoriconazole era. Antimicrob. Agents Chemother. 52, 3444-3446.

Herbrecht, R., Denning, D.W., Patterson, T.F., Bennett, J.E., Greene, R.E., Oestmann, J.W., Kern, W.V., Marr, K.A., Ribaud, P., Lortholary, O., Sylvester, R., Rubin, R.H., Wingard, J.R., Stark, P., Durand, C., Caillot, D., Thiel, E., Chandrasekar, P.H., Hodges, M.R., Schlamm, H.T., Troke, P.F., de Pauw, B, Invasive Fungal Infections Group of the European Organisation for Research and Treatment of Cancer and the Global Aspergillus Study Group, 2002. Voriconazole versus amphotericin B for primary therapy of invasive aspergillosis. N. Engl. J. Med. 347, 408-415.

Hodiamont, C.J., Dolman, K.M., ten Berge, R.J.M., Melchers, W.J.G., Verweij, P.E., et al., 2009. Multiple-azole-resistant Aspergillus fumigatus osteomyelitis in a patient with chronic granulomatous disease successfully treated with longterm oral posaconazole and surgery. Med. Mycol. 47, 217-220.

Hope, W.W., Warn, P.A., Sharp, A., Howard, S., Kasai, M., Louie, A., Walsh, T.J., Drusano, G.L., Denning, D.W., 2006. Derivation of an in vivo drug exposure breakpoint for flucytosine against Candida albicans and impact of the MIC, growth rate, and resistance genotype on the antifungal effect. Antimicrob. Agents Chemother. $50,3680-3688$.

Howard, S.J., Moore, C.B., Denning DW, 2006a. Azole resistance in Aspergillus niger. In: 2nd Advances Against Aspergillosis, Athens, Greece.

Howard, S.J., Webster, I., Moore, C.B., Gardiner, R.E., Park, S., Perlin, D.S., Denning, D.W., 2006b. Multi-azole resistance in Aspergillus fumigatus. Int. J. Antimicrob. Agents 28, 450-453.

Howard, S.J., Albarrag, A., Anderson, M.J., Gardiner, R.E., Park, S., Perlin, D., Denning, D.W., 2006c. Azole resistance in clinical Aspergillus fumigatus strains. In: 46th Interscience Conference on Antimicrobial Agents and Chemotherapy, San Francisco, USA.

Howard, S.J., Harrison, E., Bowyer, P., Denning DW, 2008. Molecular identification of clinical black Aspergillus isolates and azole resistance. In: 3rd Advances Against Aspergillosis, Miami, USA.

Howard, S.J., Cesar, D., Anderson, M.J., Albarrag, A.M., Fisher, M., Pasqualotto, A.C., Laverdiere, M., Arendrup, M.C., Perlin, D.S., Denning, D.W., 2009a. Frequency and evolution of azole resistance in Aspergillus fumigatus associated with treatment failure. Emerg. Infect. Dis. 15, 1068-1076.

Howard SJ, Pasqualotto AC, Denning DW. 2009b. Azole resistance in ABPA and Aspergillus bronchitis. Clin Microbiol. Infect. 2009, in press.

Johnson, E., Oakley, K.L., Radford, S., Moore, C.B., Warn, P., Warnock, D.W., Denning, D.W., 1999. Lack of correlation of in vitro amphotericin B susceptibility testing with outcome of in a murine model of Aspergillus infection. J. Antimicrob. Chemother. 45, 85-93.

Kontoyiannis, D.P., Lewis, R.E., May, G.S., Osherov, N., Rinaldi, M.G., 2002. Aspergillus nidulans is frequently resistant to amphotericin B. Mycoses 45, 406-407.

Krishnan, P.U., Miles, K., Shetty, N., 2002. Detection of methicillin and mupirocin resistance in Staphylococcus aureus isolates using conventional and molecular methods: a descriptive study from a burns unit with high prevalence of MRSA. J. Clin. Pathol. 55, 745-748.

Lagrou, K., De Vleeschouwer, J., Meerseman, W., et al., 2008. Triazole resistance among 229 clinical Aspergillus fumigatus isolates. In: 3rd Advances Against Aspergillosis, Miami 230, USA, Abstract 33.

Lass-Florl, C., Perkhofer, S., 2008. In vitro susceptibility-testing in Aspergillus species. Mycoses 51, 437-446.

Manavathu, E.K., Cutright, J., Chandrasekar, P.H., 1999. Comparative study of susceptibilities of germinated and ungerminated conidia of Aspergillus fumigatus to various antifungal agents. J. Clin. Microbiol. 37, 858-861.

Manavathu, E.K., Baskaran, I., Krishnan, S., Alangaden, G., Chandrasekar PH, 2003. Cytochrome P450 14-alpha-sterol demethylase mutation dependent triazole cross-resistance in Aspergillus fumigatus. In: 43rd Interscience Conference on Antimicrobial Agents and ChemotherapyPC Chicago, USA.

Mann, P.A., Parmegiani, R.M., Wei, S.Q., et al., 2003. Mutations in Aspergillus fumigatus resulting in reduced susceptibility to posaconazole appear to be restricted to a single amino acid in the cytochrome P450 14alpha-demethylase. Antimicrob. Agents Chemother. 47, 577-581.

Mavridou, E., Mouton, J.W., Brüggemann, R.J., Melchers, W.J.G., Verweij, P.E., 2008 Efficacy of posaconazole against clinical aspergillus fumigatus isolates with mutations in the cyp51a gene. In: 48th Interscience Conference on Antimicrobial Agents and Chemotherapy, Washington, USA, abstract M-2171.

Mellado, E., Garcia-Effron, G., Alcazar-Fuoli, L., Cuenca-Estrella, M., RodriguezTudela, J.L., 2004. Substitutions at methionine 220 in the 14alpha-sterol 
demethylase (Cyp51A) of Aspergillus fumigatus are responsible for resistance in vitro to azole antifungal drugs. Antimicrob. Agents Chemother. 48, 2747-2750.

Mellado, E., Garcia-Effron, G., Alcázar-Fuoli, L., Melchers, W.J., Verweij, P.E., CuencaEstrella, M., Rodríguez-Tudela, J.L., 2007. A new Aspergillus fumigatus resistance mechanism conferring in vitro cross-resistance to azole antifungals involves a combination of cyp51A alterations. Antimicrob. Agents Chemother. 51, 1897-1904.

Mosquera, J., Denning, D.W., 2002. Azole cross-resistance in Aspergillus fumigatus. Antimicrob. Agents Chemother. 46, 556-557.

Mosquera, J., Warn, P.A., Morrissey, J., Moore, C.B., Gil-Lamaignere, C., Denning, D.W., 2001. Susceptibility testing of Aspergillus flavus: inoculum dependence with itraconazole and lack of correlation between susceptibility to amphotericin B in vitro and outcome in vivo. Antimicrob. Agents Chemother. 45, 1456-1462.

Nascimento, A.M., Goldman, G.H., Park, S., et al., 2003. Multiple resistance mechanisms among Aspergillus fumigatus mutants with high-level resistance to itraconazole. Antimicrob. Agents Chemother. 47, 1719-1726.

National Committee for Clinical Laboratory Standards, 2002. Reference method for broth dilution antifungal susceptibility testing of filamentous fungi. National Committee for Clinical Laboratory Standards, Wayne, PA, Approved standard M38-A.

Oakley, K.L., Morrissey, G., Denning, D.W., 1997. Efficacy of SCH-56592 in a temporarily neutropenic murine model of invasive aspergillosis with an itraconazole-susceptible and an itraconazole-resistant isolate of Aspergillus fumigatus. Antimicrob. Agents Chemother. 41, 1504-1507.

Pfaller, M.A., Messer, S.A., Boyken, L., Rice, C., Tendolkar, S., Hollis, R.J., Diekema, D.J., 2008. In Vitro survey of triazole cross-resistance among more than 700 clinical isolates of Aspergillus species. J. Clin. Microbiol. 46, 2568-2572.

Rambali, B., Fernandez, J.A., Van Nuffel, L., Woestenborghs, F., Baert, L., Massart, D.L., Odds, F.C., 2001. Susceptibility testing of pathogenic fungi with itraconazole: a process analysis of test variables. J. Antimicrob. Chemother. 48, 163-177.

Rex, J.H., Pfaller, M.A., Galgiani, J.N., Bartlett, M.S., Espinel-Ingroff, A., Ghannoum, M.A., Lancaster, M., Odds, F.C., Rinaldi, M.G., Walsh, T.J., Barry, A.L., 1997. Development of interpretive breakpoints for antifungal susceptibility testing: conceptual framework and analysis of in vitro-in vivo correlation data for fluconazole, itraconazole, and Candida infections. Subcommittee on Antifungal Susceptibility Testing of the National Committee for Clinical Laboratory Standards. Clin. Infect. Dis. 24, 235-247.

Rodríguez-Tudela, J.L., Almirante, B., Rodríguez-Pardo, D., Laguna, F., Donnelly, J.P., Mouton, J.W., Pahissa, A., Cuenca-Estrella, M., 2007. Correlation of the MIC and dose/MIC ratio of fluconazole to the therapeutic response of patients with mucosal candidiasis and candidemia. Antimicrob. Agents Chemother. 51, 3599-3604.

Subcommittee of Antifungal Susceptibility Testing of the European Committee for Antimicrobial Susceptibility Testing of the European Society of Clinical Microbiology and Infectious Diseases, 2007. Method for the determination of broth dilution minimum inhibitory concentrations of antifungal agents for conidia forming moulds.

Slaven, J.W., Anderson, M.J., Sanglard, D., et al., 2002. Increased expression of a novel Aspergillus fumigatus ABC transporter gene, atrF, in the presence of itracona- zole in an itraconazole resistant clinical isolate. Fungal Genet. Biol. 36, 199206

Snelders, E., van der Lee, H.A.L., Kuijpers, J., Rijs, A.J.M.M., Varga, J., Samson, R.A., Mellado, E., Melchers, W.J.G., Verweij, P.E., 2008. Emergence of azole resistance in Aspergillus fumigatus and spread of a single resistance mechanism. PLoS Med. 5, e219.

Snelders, E., Huis In ‘t Veld, R.A., Rijs, A.J., Kema, G.H., Melchers, W.J., Verweij, P.E., 2009. Possible environmental origin of resistance of Aspergillus fumigatus to medical triazoles. Appl. Environ. Microbiol. 75, 4053-4057.

Steinbach, W.J., Benjamin Jr., D.K., Kontoyiannis, D.P., Perfect, J.R., Lutsar, I., Marr K.A., Lionakis, M.S., Torres, H.A., Jafri, H., Walsh, T.J., 2004. Infections due to Aspergillus terreus: a multicenter retrospective analysis of 83 cases. Clin. Infect. Dis. 39, 192-198.

Ullmann, A.J. Lipton, J.H. Vesole, D.H. Chandrasekar, P., Langston, A. Tarantolo, S.R. Greinix, H., Morais de Azevedo, W., Reddy, V., Boparai, N., Pedicone, L., Patino, H., Durrant, S., 2007. Posaconazole or fluconazole for prophylaxis in severe graftversus-host disease. N. Engl. J. Med. 356, 335-347.

Varga, J., Houbraken, J., Van Der Lee, H.A., Verweij, P.E., Samson, R.A., 2008. Aspergillus calidoustus sp. nov., causative agent of human infections previously assigned to Aspergillus ustus. Eukaryot. Cell 7, 630-638.

Van der Linden, J.W.M., Snelders, E., Debets, Y., Kampinga, G.A., Kuijper, E., Mattson, E., Rijnders, B., van Tiel, F.H., Visser, C., Melchers, W.J.G., Verweij PE, 2008. Prospective study of the prevalence of azole resistance in aspergillus species in the Netherlands. In: 48th Interscience Conference on Antimicrobial Agents and Chemotherapy, Washington, abstract M-1718.

Van der Linden, J.W.M., Jansen, R.R., Bresters, D., Visser, C.E., Geerlings, S.E., Kuijper, E.J., Melchers, W.J.G., Verweij, P.E., 2009. Azole resistant central nervous system aspergillosis. Clin. Infect. Dis. 48, 1441-1458.

Verweij, P.E., Mellado, E., Melchers, W.J., 2007. Multiple-triazole-resistant aspergillosis. N. Engl. J. Med. 356, 1481-1483.

Walsh, T.J., Petraitis, V., Petraitiene, R., Field-Ridley, A., Sutton, D., Ghannoum, M., Sein, T., Schaufele, R., Peter, J., Bacher, J., Casler, H., Armstrong, D., Espinel-Ingroff, A., Rinaldi, M.G., Lyman, C.A., 2003. Experimental pulmonary aspergillosis due to Aspergillus terreus: pathogenesis and treatment of an emerging fungal pathogen resistant to amphotericin B. J. Infect. Dis. 188, 305319.

Walsh, T.J., Anaissie, E.J., Denning, D.W., Herbrecht, R., Kontoyiannis, D.P., Marr, K.A., Morrison, V.A., Segal, B.H. Steinbach, W.J. Stevens, D.A, van Burik, J.A., Wingard, J.R., Patterson, T.F., 2008. Infectious Diseases Society of America. Treatment of aspergillosis: clinical practice guidelines of the Infectious Diseases Society of America. Clin. Infect. Dis. 46, 327-360.

Warris, A., Weemaes, C.M., Verweij, P.E., 2002. Multidrug resistance in Aspergillus fumigatus. N. Engl. J. Med. 347, 2173-2174.

Xiao, L., Madison, V., Chau, A.S., Loebenberg, D., Palermo, R.E., McNicholas, P.M., 2004. Three-dimensional models of wild-type and mutated forms of cytochrome P450 14 $\alpha$-sterol demethylases from Aspergillus fumigatus and Candida albicans provide insights into posaconazole binding. Antimicrob. Agents Chemother. 48 , 568-574. 